\title{
¿Higiea o Panacea?
}

Pedro Gargantilla-Madera, Noelia Arroyo-Pardo, Emilio Pintor-Holguín

'Juro por los médicos y Esculapio, y por Higiea y Panacea, y por todos los dioses y diosas, poniéndolos de jueces... [1], así comienza el juramento hipocrático. Ahora bien, ¿sabemos realmente qué implica jurar por Higiea y Panacea?

Según la mitología, Asclepio, el dios de la salud por antonomasia en la civilización griega, era hijo de Corónide, una bella mortal, y de Apolo, uno de los dioses más importantes del panteón griego. Asclepio tuvo varios hijos, entre ellos Higiea y Panacea. Higiea era la diosa de la curación, la limpieza y la sanidad; de su nombre deriva el término 'higiene' [2]. A esta diosa habitualmente se la representaba como una mujer joven que alimenta a una gran serpiente enroscada en torno a su cuerpo. Esta divinidad se asoció con la prevención de la enfermedad y la continuación de la buena salud [2]. Por su parte, Panacea era la diosa de la salud; su nombre se compone de pan ('todo') y akos ('remedio'), por lo que 'panacea' significa literalmente aquello que es 'capaz de curar diversas enfermedades'.

Durante siglos, las sociedades prefirieron la dualidad Asclepio/Panacea, es decir, el enfoque de la salud entendido como curación quirúrgica (Asclepio) o farmacológica (Panacea): el ser humano aprende a dominar las enfermedades a través del conocimiento de las plantas o minerales y de la tecnología quirúrgica. Este hecho se traduce en el momento actual en la búsqueda de nuevos fármacos, vacunas o tecnologías que permitan llegar a diagnósticos más precisos.
La otra vertiente de la salud, la cara oculta, es Higiea, la cual ha permanecido postergada porque no enseña fórmulas nuevas ni curas milagrosas; muy al contrario, Higiea enseña el camino de la moderación y la razonabilidad. Sin embargo, la crisis económica actual ha facilitado que los médicos defendamos aquellas formas de conducta reguladas por el ethos, esto es, el elemento implícito, pero no obligatorio, para conducirnos en la vida. Sin embargo, no debemos engañarnos: las condiciones que plantea Higiea, entre ellos realizar cambios en el estilo de vida, no son nada sencillas y en numerosas ocasiones no nos gustan.

En estos momentos, ¿por qué debemos abogar por Higiea o por Panacea? En cierta ocasión, el político estadounidense Benjamín Franklin (17061790) afirmó que 'una onza de prevención vale tanto como una libra de curación. Recordemos que una onza equivale a 28,35 gramos, y una libra, a 453,54 gramos.

Para terminar, nos quedamos con una frase de George Bernard Shaw que aparece en su obra teatral El dilema del médico: 'utilice su salud lo mejor que pueda y no trate de vivir eternamente, no lo conseguirá.

\section{Bibliografía}

1. Guthrie D. Historia de la medicina. Barcelona: Salvat Editores; 1947.

2. Gargantilla P. Manual de historia de la medicina. 4 ed. Málaga: Grupo Editorial 33; 2013.
Universidad Europea de Madrid (P. Gargantilla-Madera, E. PintorHolguín). Servicio de Medicina Interna; Hospital El Escorial (P. GargantillaMadera, N. Arroyo-Pardo). Madrid, España.

Correspondencia:

Dr. Pedro Gargantilla Madera. Servicio de Medicina Interna. Hospital El Escorial. Ctra. M-600 de Guadarrama a San Lorenzo de El Escorial, km 6,255. E-28200 San Lorenzo de El Escorial (Madrid).

E-mail: pgargantilla@yahoo.es (c) 2015 FEM 